\title{
32.P15
}

\section{Process of Neurite Formation and Genetic Engineering}

\author{
Hiroshi K. Inoue, Masaru Nakamura and Tomoaki Shirao \\ Department of Neurosurgery, Gunma University School of Medicine, \\ Showa-machi, Maebashi, 371 and Department of Physiology, Keio University \\ School of Medicine, Shinano-Machi, Shinjuku-ku, Tokyo, 160, Japan
}

The process of neurite formation is an important event in neurobiology, especially for brain development, differentiation and nerve regeneration. The ultrastructural changes associated with neurite formation were examined using neuroblastoma cells and Drebrin (developmentally regulated brain protein) gene transfected cells in culture. Neurite formation of neuroblastoma cells was induced by serum-free medium. Neurite-like processes were induced by transfection of the Drebrin gene into fibroblast cells. Those cells were observed on scanning electron microscopy, whole mount electron microscopy and thin section electron microscopy. Both original neuroblastoma cells and fibroblast cells were large, flattened and epitheloid in shape and had many microspikes and/or microvilli diffusely on their surfaces and cell borders. Intracellular organelles were abundant and had a diffuse arrangement and no special organization. Both transformed cells with long processes were round or oval and microspikes were concentrated on the processes. A few organelles were shown in narrow perinuclear cytoplasm. Mitochondria and abundant filamentous structures were found in processes. A constant arrangement and organization were shown in surface and intracellular structures. However, Drebrin gene transfected cells still had some characteristics of the original fibroblast such as microvilli on their surfaces, polygonal shape of the cell body and irregular bundles of intermediate filaments in long processes. Ultrastructures of neurites and cell bodies of neuroblastoma cells are similar to those of neuronal cells. The neurite formation programmed by genes may be initiated by some factors in neuroblastoma cells. However, ultrastructures of neurite-like processes and cell bodies of Drebrin gene transfected cells still have characteristics of original fibroblasts. Neurite-like processes with microspikes may be formed due to the change of microfilaments by transfection of the Drebrin gene into fibroblast cells. 

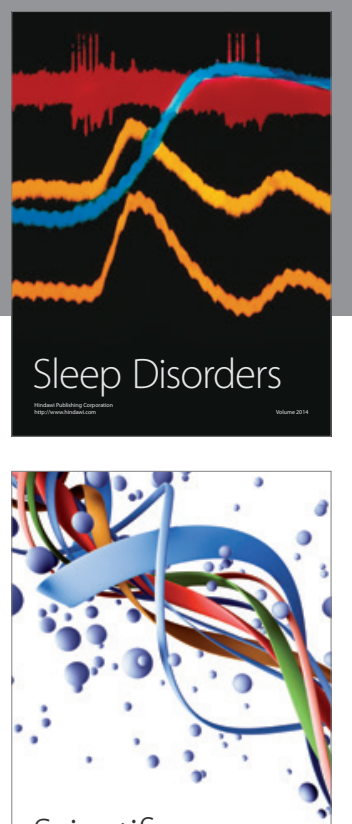

Scientifica
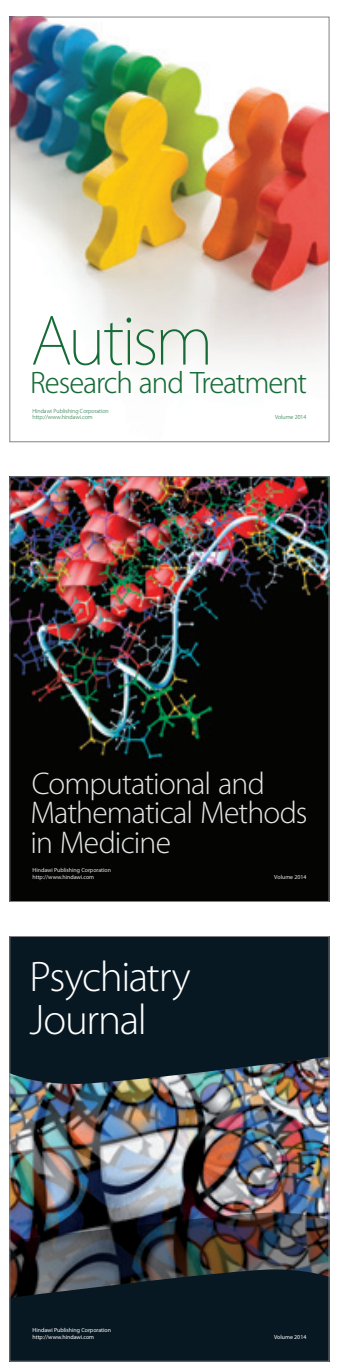
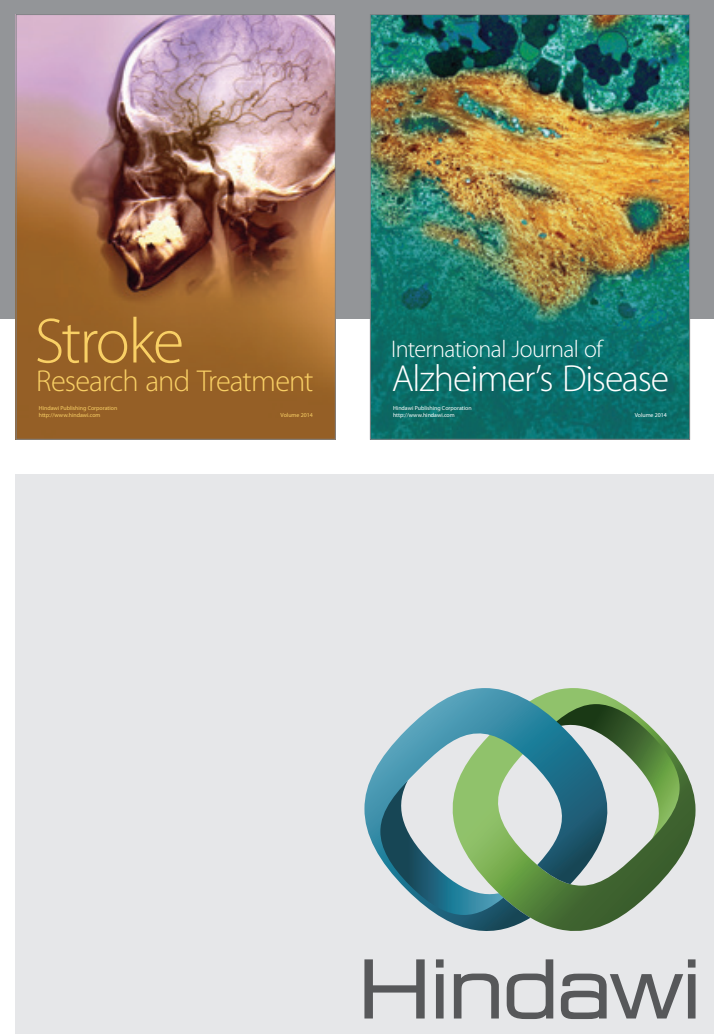

Submit your manuscripts at

http://www.hindawi.com
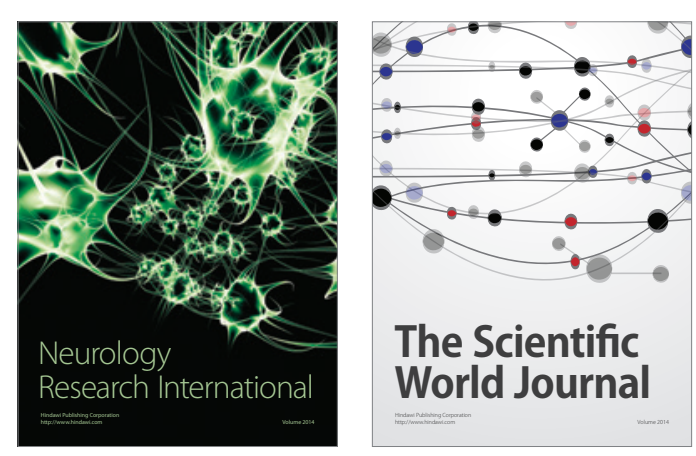

The Scientific World Journal

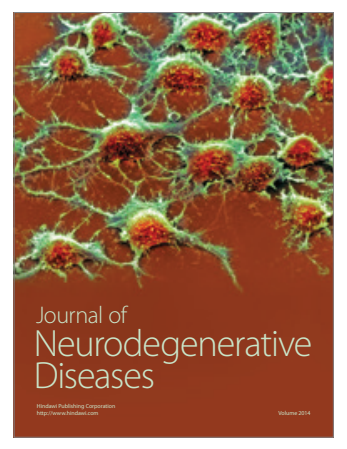

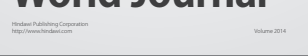

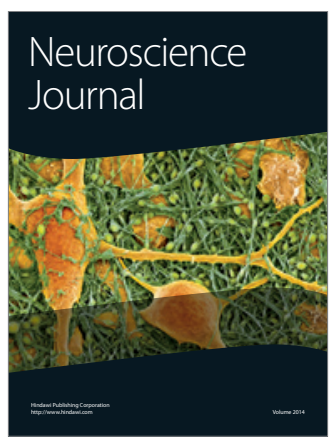

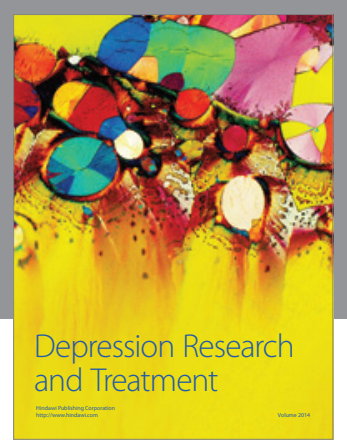
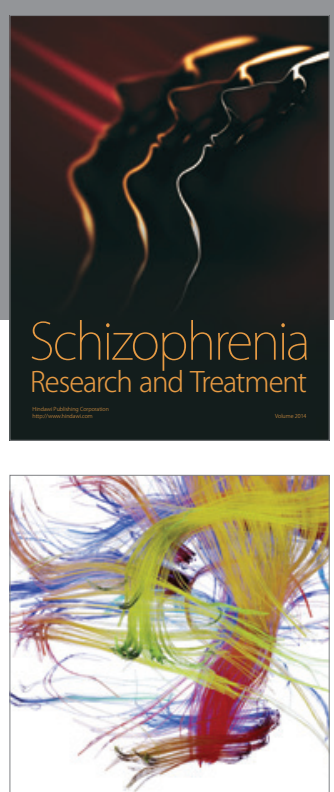

Brain Science

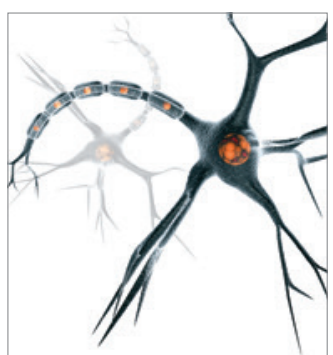

Neural Plasticity
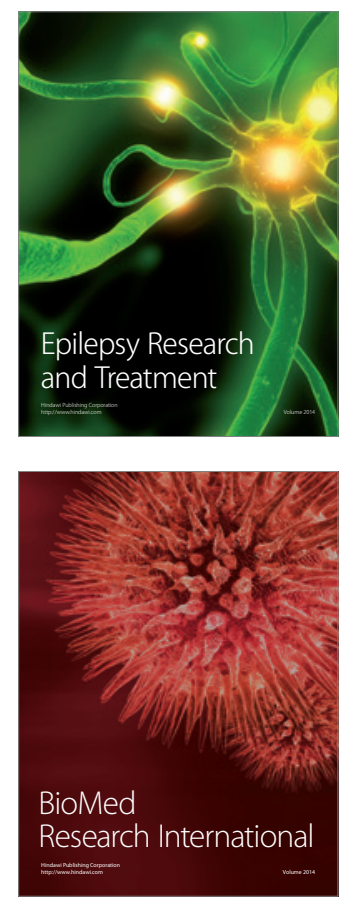

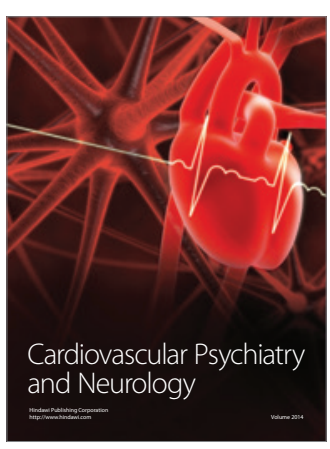

Parkinson's

Disease
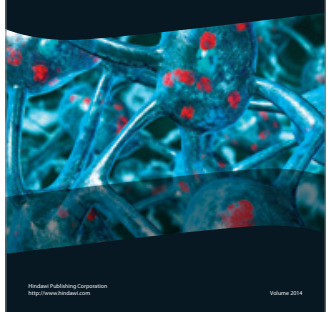